\title{
Oceanography
}

CITATION

Orcutt, B.N., and I. Cetinić. 2014. Women in oceanography: Continuing challenges.

Oceanography 27(4) supplement:5-13, http://dx.doi.org/10.5670/oceanog.2014.106.

DOI

http://dx.doi.org/10.5670/oceanog.2014.106

COPYRIGHT

This article has been published in Women in Oceanography, a supplement to Oceanography, Volume 27, Number 4. Oceanography is the quarterly journal of The Oceanography Society. Copyright 2014 by The Oceanography Society. All rights reserved.

USAGE

Permission is granted to copy this article for use in teaching and research. Republication, systematic reproduction, or collective redistribution of any portion of this article by photocopy machine, reposting, or other means is permitted only with the approval of The Oceanography Society. Send all correspondence to: info@tos.org or The Oceanography Society, PO Box 1931, Rockville, MD 20849-1931, USA. 


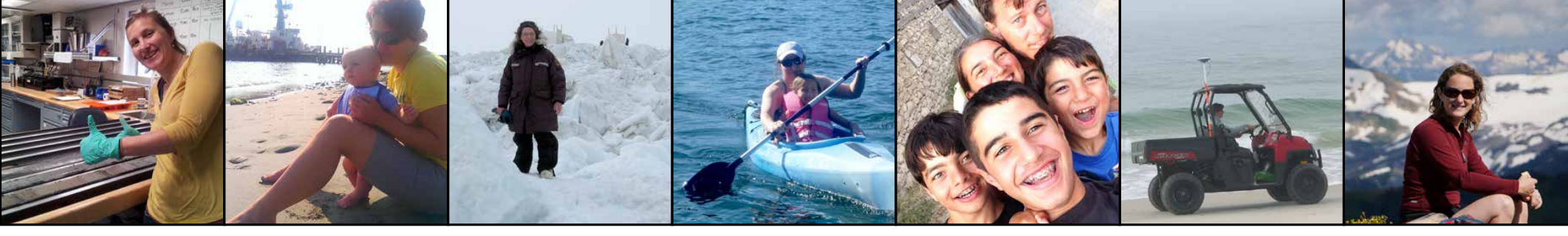

\section{Women in Oceanography: Continuing Challenges}

By Beth N. Orcutt and Ivona Cetinić

ABSTRACT. Women began to join US oceanographic expeditions in about 1960, contemporary with the modern women's rights movements in the industrialized world. Female representation in academic research has increased since then, but the ratio of women to men at higher ranks in oceanography still lags, even though women have comprised roughly half of oceanography graduate students during the past decade. Here, we examine recent trends in the representation of women in oceanography, highlighting indicators of under-representation among oceanographic faculty and chief scientists of oceanographic expeditions, and also noting positive signs of improvement. We discuss modern challenges to women in academic science, and oceanography in particular, and how they influence the career choices of women in oceanography. We provide recommendations for overcoming internal and external obstacles to career success that should be useful to students and early career women oceanographers as well as search committees, deans, department chairs, and program managers who have the power to hire and promote female colleagues.

\section{INTRODUCTION}

Significant contributions of women to the scientific investigation of the ocean have been relatively recent. With very few exceptions, the genesis of ocean-going women oceanographers in the Western world can be traced to the late 1950s and early 1960s, as detailed in Bonatti and Crane's (2012) article on the early challenges of women in oceanography. Remarkably, the first female oceanographer allowed to sail on a United States oceanographic expedition in her own rightBetty Bunce of the Woods Hole Oceanographic Institutionwas also the 1959 expedition's chief scientist. Bunce also has the honor of being the first woman scientist to dive in the Alvin submersible and the first female chief scientist in the Deep Sea Drilling Project (Lavoie and Hutchinson, 2005). The women who preceded her at sea-Jeanne Baret French in the 1760s, Marie Poland Fish in the 1920s, Helen Raitt and Barbara Lawrence in the early 1950s, and Roberta Eike in the mid 1950s-stowed away, dressed as a man, or were only permitted to sail because their husbands were also on board. However, these trail-blazing women set the stage for future generations of female oceanographers.

As early career female oceanographers puzzled by the relative dearth of female role models at the top levels of academic oceanography, we set out to examine the modern trends and obstacles to female participation in our field, based on efforts that began a decade ago to understand and tackle this issue (Bell et al., 2005; Lavoie and Hutchinson, 2005; Lozier, 2005; Marcus, 2005; O’Connell and Holmes, 2005). Undoubtedly, since the early 1960s, the acceptance of women at sea has improved, yet the representation of women in top levels of oceanography today remains low. This article presents broad trends related to the general challenges women encounter in science and then chronicles the current state of women in oceanographic academia. We focus on statistics from the United States, where we are oceanographers, but include data from other countries where available. We offer this analysis with the hope that it will provide guidance to students 
considering a career in oceanography, to early career women navigating the career ladder, and to search committees, deans, department chairs, and program managers who make decisions that affect women in oceanography.

\section{WOMEN IN SCIENCE IN THE UNITED STATES}

The percentages of female role models in US academic faculty remain remarkably low, even several decades after enactment of equal opportunity and antidiscrimination laws, including Title IX (1990) and the Women in Science and Technology Equal Opportunity Act (1990). This paucity is not likely due to a lack of women in the pipeline (Shen, 2013), as determined by a National Science Foundation survey (NSF, 2013) and summarized in Table 1. For example, over the past decade, more than half of all science and engineering undergraduates were women $(57 \%)$, more than half of bachelor's degrees (56\%) and master's degrees (52-54\%) have been awarded to women, and nearly half of doctoral degrees (44-47\%) were earned by women (NSF, 2013). In contrast, women employed in the academic ranks of science and engineering fields at four-year universities comprised only $43 \%$ of the assistant professor level, $34 \%$ at the associate professor level, and $21 \%$ at the full professor level (NSF, 2013). Moreover, only $26 \%$ of currently tenured professors and only $39 \%$ of tenure-track professors are women (NSF, 2013). These data show that the gender gap is smaller at the junior faculty level than at the senior faculty level; women comprise $43 \%$ of assistant professors, similar to the percentage of women awarded doctoral degrees over the past 10 years (NSF, 2013).

\section{WOMEN IN OCEANOGRAPHY}

To better understand how women academics in oceanography are faring, we examined trends for women in leadership roles, including percentages of women faculty at oceanographic

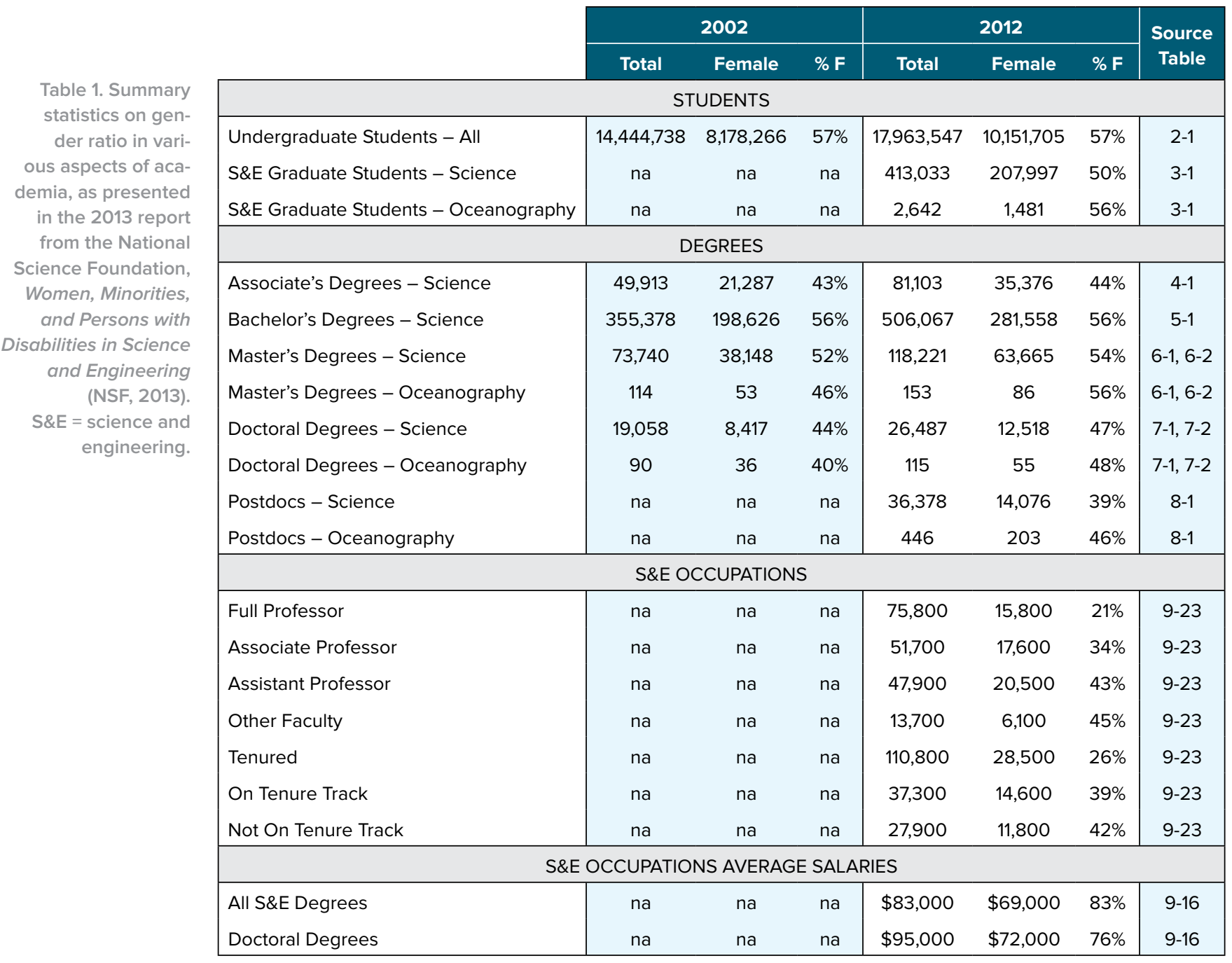


institutions and of chief scientists on oceanographic research expeditions, as compared to the percentages of women who earned oceanographic PhDs in the United States from a few years ago to just over a decade ago (Tables 1, 2; Figures 1,2). Our analysis shows that women continue to drop out as they progress along the tenure track, similar to the patterns identified across all fields of science mentioned above, as well as to results of similar but smaller surveys presented elsewhere (O'Connell and Holmes, 2005; Thompson et al., 2011;
O'Connell, 2014, in this supplement). However, there are also some signs of improvement over the past decade.

Examining current faculty gender ratios at 26 major oceanography programs in the United States reveals several trends (Table 2, Figure 1). First, the median percentage of females at all faculty levels is lower than expected given the percentage of oceanography doctoral degrees awarded in the past decade or more (compare to Table 1). Second, the percentage of females decreases with increasing faculty rank, from $40 \%$

Table 2. Gender ratio of student population and current faculty in major oceanography programs in the United States, sorted by student population size. Student population demographics were gathered from publicly available data from the Peterson's Nelnet LLC online database in fall 2014, and faculty demographics from publicly available institution websites in fall 2014 (excluding emeritus and adjunct faculty). Note that student numbers do not separate undergraduate versus graduate level students.

\begin{tabular}{|c|c|c|c|c|c|c|c|c|}
\hline \multirow[b]{2}{*}{ Institution } & \multicolumn{2}{|c|}{ Students } & \multicolumn{2}{|c|}{ Assistant Professor } & \multicolumn{2}{|c|}{ Associate Professor } & \multicolumn{2}{|c|}{ Full/Senior Professor } \\
\hline & $\begin{array}{c}\text { Total } \\
\#\end{array}$ & $\begin{array}{c}\% \\
\text { Female }\end{array}$ & $\begin{array}{c}\text { Total } \\
\#\end{array}$ & $\begin{array}{c}\% \\
\text { Female }\end{array}$ & $\begin{array}{c}\text { Total } \\
\#\end{array}$ & $\begin{array}{c}\% \\
\text { Female }\end{array}$ & $\begin{array}{c}\text { Total } \\
\#\end{array}$ & $\begin{array}{c}\% \\
\text { Female }\end{array}$ \\
\hline Scripps Institution of Oceanography & 269 & $47 \%$ & 14 & $29 \%$ & 11 & $27 \%$ & 74 & $16 \%$ \\
\hline MIT/WHOI* Joint Program & 128 & $48 \%$ & 37 & $27 \%$ & 60 & $23 \%$ & 107 & $18 \%$ \\
\hline University of South Florida & 102 & $59 \%$ & 5 & $40 \%$ & 8 & $25 \%$ & 13 & $15 \%$ \\
\hline University of Washington & 78 & $51 \%$ & 13 & $23 \%$ & 20 & $30 \%$ & 42 & $21 \%$ \\
\hline Louisiana State University & 77 & $56 \%$ & 7 & $14 \%$ & 9 & $22 \%$ & 14 & $0 \%$ \\
\hline University of Hawaii & 77 & $58 \%$ & 0 & $0 \%$ & 10 & $30 \%$ & 44 & $14 \%$ \\
\hline University of Rhode Island & 73 & $63 \%$ & 2 & $0 \%$ & 5 & $100 \%$ & 20 & $15 \%$ \\
\hline Texas A\&M University & 70 & $50 \%$ & 1 & $100 \%$ & 4 & $50 \%$ & 14 & $14 \%$ \\
\hline University of Colorado Boulder & 60 & $47 \%$ & 4 & $100 \%$ & 4 & $25 \%$ & 4 & $25 \%$ \\
\hline University of Alaska Fairbanks & 58 & $69 \%$ & 13 & $46 \%$ & 10 & $40 \%$ & 23 & $35 \%$ \\
\hline University of Massachusetts Dartmouth & 58 & $47 \%$ & 3 & $0 \%$ & 4 & $0 \%$ & 15 & $13 \%$ \\
\hline Florida State University & 57 & $51 \%$ & 6 & $50 \%$ & 0 & $0 \%$ & 11 & $9 \%$ \\
\hline University of Maine & 54 & $56 \%$ & 2 & $50 \%$ & 6 & $67 \%$ & 19 & $21 \%$ \\
\hline University of Southern Mississippi & 53 & $42 \%$ & 3 & $0 \%$ & 4 & $0 \%$ & 5 & $20 \%$ \\
\hline Oregon State University & 46 & $50 \%$ & 23 & $48 \%$ & 23 & $13 \%$ & 56 & $20 \%$ \\
\hline College of Charleston & 45 & $73 \%$ & 10 & $40 \%$ & 15 & $40 \%$ & 9 & $0 \%$ \\
\hline University of Miami & 42 & $24 \%$ & 4 & $50 \%$ & 18 & $44 \%$ & 51 & $6 \%$ \\
\hline University of California, Santa Cruz & 40 & $65 \%$ & 2 & $100 \%$ & 1 & $0 \%$ & 6 & $33 \%$ \\
\hline University of North Carolina, Chapel Hill & 40 & $58 \%$ & 4 & $0 \%$ & 3 & $0 \%$ & 14 & $21 \%$ \\
\hline Old Dominion University & 38 & $55 \%$ & 5 & $20 \%$ & 11 & $45 \%$ & 7 & $0 \%$ \\
\hline University of Connecticut & 38 & $58 \%$ & 4 & $75 \%$ & 7 & $43 \%$ & 9 & $11 \%$ \\
\hline University of Georgia & 32 & $56 \%$ & 6 & $33 \%$ & 9 & $33 \%$ & 11 & $27 \%$ \\
\hline Rutgers University & 29 & $66 \%$ & 5 & $80 \%$ & 4 & $50 \%$ & 21 & $5 \%$ \\
\hline University of California, Santa Barbara & 21 & $67 \%$ & 0 & $0 \%$ & 2 & $50 \%$ & 23 & $17 \%$ \\
\hline University of Delaware & na & $53 \%$ & 12 & $50 \%$ & 17 & $29 \%$ & 29 & $14 \%$ \\
\hline University of Southern California & na & na & 1 & $100 \%$ & 4 & $25 \%$ & 13 & $8 \%$ \\
\hline
\end{tabular}

* MIT/WHOI: Massachusetts Institute of Technology/Woods Hole Oceanographic Institution 
at the assistant professor level to $30 \%$ at the associate professor level to $15 \%$ at the full or senior faculty level. This trend is consistent with those observed earlier for the field of oceanography (Marcus, 2005; O'Connell and Holmes, 2005) and in a more recent survey (O'Connell, 2014, in this supplement). However, it is worth noting that the percentages of women at all levels have increased by roughly $5 \%$ to $15 \%$ in the past decade. For example, an earlier study reported oceanography faculty-rank female gender percentages of $25-30 \%$ at the assistant professor level, $17-25 \%$ at the associate professor level, and roughly $10 \%$ at full professor level (O'Connell and Holmes, 2005), while more current assessments indicate increases to $35 \%, 33 \%$, and roughly $20 \%$ at the assistant, associate, and full professor levels, respectively (O'Connell, 2014, in this supplement). While the percentages reported here vary from those reported elsewhere (O'Connell, 2014, in this supplement), note that our analysis includes 26 oceanographic institutions whereas other analyses include far fewer programs, and all may suffer from the statistics of small numbers. The final trend is the larger variation at lower faculty ranks, where some programs have $100 \%$ female faculty, which may reflect increased efforts at female recruitment for lower rank positions.

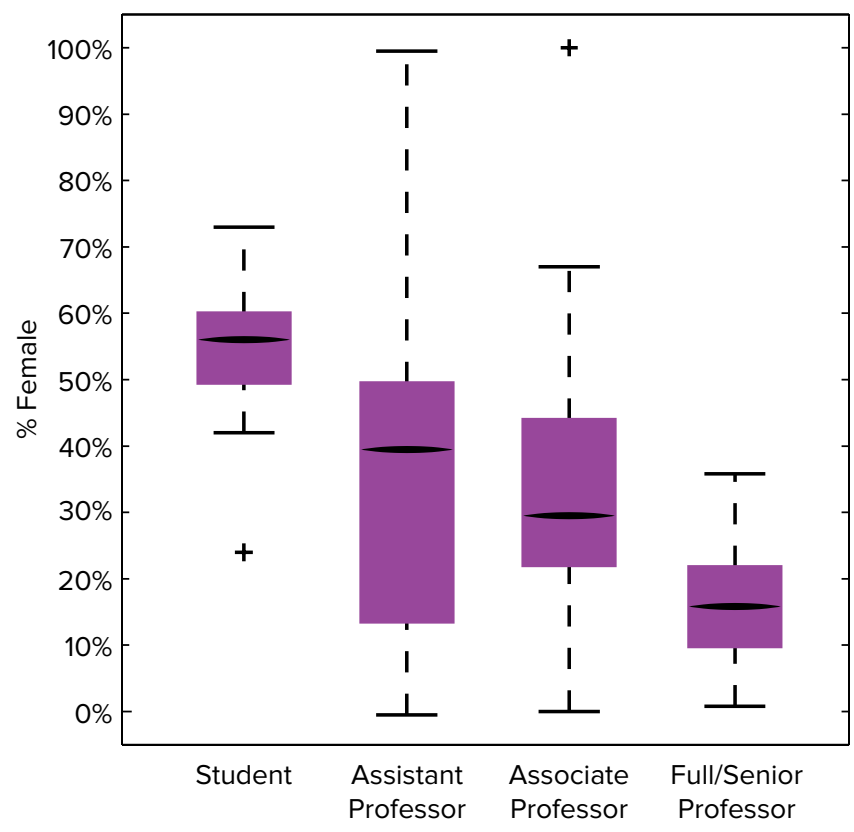

Figure 1. Box-and-whisker plot of the median, upper and lower quartiles, and maximum and minimum female representation in student population and assistant, associate, and full/senior professors for major oceanographic programs in the United States, based on the data presented in Table 2 . Outliers are depicted by + symbol.
Although less than $30 \%$ of chief scientists on research vessels in the last decade have been women, the trend is improving (Figure 2). We surveyed various national and international programs, including the ocean drilling programs (Deep Sea Drilling Project, 1969-1986; Ocean Drilling Program, 1986-2003; and Integrated Ocean Drilling Program, 2003-2013), the US national research fleet coordinated by UNOLS (the University-National Oceanographic Laboratory System; data available from 2000 to 2014), the German Polarstern research vessel (data from 1998-2013), the Alliance research vessel of the North Atlantic Treaty Organization (NATO; data from 1999-2013), the private sailing research vessel Tara of French Tara Expeditions (data from 2009-2014), and the private research vessel Falkor of the Schmidt Ocean Institute (data from 2012-2014). This analysis shows that the percentage of female chief scientists has generally doubled in the last decade from roughly $10 \%$ to $20 \%$ on UNOLS vessels and from 15 to $30 \%$ on Polarstern, though the percentage of women co-chief scientists on drilling vessels remains low (12\%). These percentages are roughly equal to the percentage of women in full professor or senior researcher ranks in US oceanography programs, but lower than those at the assistant or associate professor level (Table 2, Figure 1).

The low percentage of female chief scientists on research expeditions in the past decade, in comparison to the percentage of women in oceanographic academia, may indicate that fewer women than men are proposing seagoing research. In the United States, chief scientists are typically the principal investigators of successfully funded projects and are not chosen through a formal application process. However, this metric is difficult to quantify, because the ratio of male to female proponents of successful and unsuccessful proposals with ship time requests is not publicly available, to our knowledge. For the ocean drilling programs, co-chief scientists are most often selected for an expedition from the initial proponents of a drilling proposal. It can take years to schedule a drilling leg, and if women are not involved in the initial scoping and proposing stage of a project, it is unlikely that they will be considered for co-chief scientist positions.

Where it is possible to evaluate the gender ratio of cruise participants, such as in the ocean drilling programs, the percentage of female participants can be seen to have increased through the Ocean Drilling Program toward 30\% (O’Connell and Holmes, 2005) but to have become more erratic in the Integrated Ocean Drilling Program (see O'Connell, 
2014, in this supplement). However, observations suggest that the ratio of female to male cruise participants roughly matches the gender ratio in the applicant pool (J. Schuffert, Consortium for Ocean Leadership, pers. comm., 2014).

\section{MODERN CHALLENGES TO ACADEMIC WOMEN IN SCIENCE}

To provide some explanation for the trends we found regarding women in scientific leadership positions, and in oceanography in particular, we explored the array of challenges women face.

The possibilities for women to transition to higher levels in academia begin at the hiring level. Some have argued that the lower proportion of female applications for tenure-track jobs, as compared to degree holders, could reflect the notion that women do not see other women in these positions (i.e., they do not see people like themselves; Handelsman et al., 2005; Shen, 2013). Others have shown that starting a career in a non-tenure-track position, which women may accept more frequently than men, often does not lead to a tenure-track position (Schuster and Finkelstein, 2006). In terms of advancement once a tenure-track position is secured, recent studies show that gender bias and discrimination, harassment, and lack of resources for sustaining a family while building a career are some key reasons that women do not advance academically (see further discussion below).

Gender bias, both conscious and unconscious, may contribute to the loss of women from the academic pipeline (Hill et al., 2010). For example, a recent study documented the tendency for elite male scientists to discriminate against females when hiring postdoctoral scientists (Sheltzer and Smith, 2014). Other recent studies found that conference sessions chaired exclusively by men also strongly select for male presenters over female presenters (Isbell et al., 2012; Casadevall and Handelsman, 2014). Yet another study documented that papers authored by women received fewer citations than those authored by men (Larivière et al., 2013). It was also found that both women and men would offer male candidates more money and mentoring in a scientific position when given fictitious resumes for candidates, with the (equal on paper) female candidate perceived as less competent (Moss-Racusin et al., 2012). Gender bias is also evident in some peer-review processes for fellowship applications, where male achievements are over-estimated and female achievements are under-estimated (Wennerås and Wold, 1997), though we cannot say whether bias remains in the 18 years since this study was conducted. There is a tendency for women in academia to be invited (or required) to participate in committees and projects because male colleagues "need a woman" to round out diversity (Park, 1996; Handelsman et al., 2005). Such invitations leave female academics feeling that their utility is solely based on their gender rather than their accomplishments, and experiencing burnout faster than male colleagues (Marcus, 2005).

Biases against women obtaining research funding have also been noted. For example, a recent study documented that the average size of US National Institutes of Health (NIH) research grants awarded to women is $83 \%$ of grants to men (Shen, 2013). However, the gender ratio of women on NIH grant panels that made funding recommendations

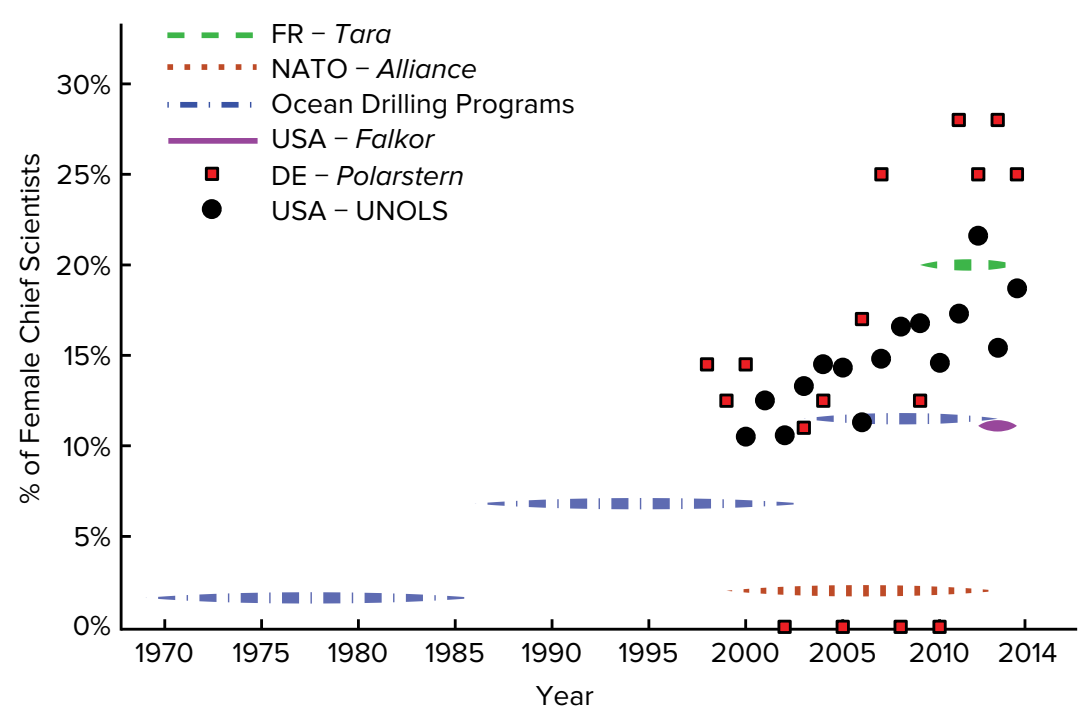

Figure 2. Percentage of female chief scientists on oceanographic cruises from several representative programs over the past 50 years. While UNOLS (University-National Oceanographic Laboratory System) and R/V Polarstern data report yearly values, other data sets show values for respective time periods. Vessels and programs represented are the French Sailing Vessel Tara of Tara Expeditions; the NATO (North Atlantic Treaty Organization) Research Vessel Alliance; the German Research Vessel Polarstern; the US R/V Falkor of Schmidt Ocean Institute and the US vessels managed under the UNOLS umbrella. The data presented for "Ocean Drilling Programs" represent the Deep Sea Drilling Project (1969-1986), the Ocean Drilling Program (1986-2003), and the Integrated Ocean Drilling Program (2003-2013). 
was similar to the gender ratio of grant applicants, suggesting that gender bias in review committee composition was not a factor in this outcome (Shen, 2013). In contrast, recent reports from the US National Science Foundation (NSF), which funds a majority of academic oceanographic research, indicate that the number of proposals submitted by women to the Division of Ocean Sciences increased from one in five to one in four over the 2002-2012 period; within this time period, the average success rate of proposals submitted by women was roughly equal to or $5-10 \%$ lower than the success rate for men, although this varied by program and did not show a clear trend (NSF, 2012). The percentage of female panelists ranged from $15-22 \%$ and proposal reviewers from $17-32 \%$ for the period 2009-2011 (NSF, 2012), which is in the same range as the proportion of women in academic positions (Table 2) and the percentage of female-led proposal submissions.

Recent studies show that there is a continuing-and inexcusable-threat of sexual harassment in the scientific work place (as in other professional settings), demonstrated in a survey on sexual harassment or assault in fieldwork settings (Clancy et al., 2014). While it may be possible that those who experienced harassment and assault were more likely to complete the survey, two-thirds of respondents (i.e., over 400 people) claimed to have experienced sexual harassment in the field, with more than $20 \%$ reporting sexual assault (Clancy et al., 2014). A recent survey of science writers showed similar trends, with almost half of respondents (mostly women) claiming sexual harassment in the workplace and 20\% reporting uninvited physical contact (Aschwanden, 2014). Moreover, respondents commonly lacked appropriate mechanisms for reporting and addressing such issues, which erodes women's empowerment to resolve incidences and effect change to prevent future occurrences. Hence, we are in a situation many decades after enactment of anti-discrimination laws where bias and harassment continue to affect the progress of women in professional careers.

Unlike the Clancy et al. (2014) study that surveyed the prevalence of sexual harassment and assault across a broad swath of scientific fields, we know of no formal report or survey of these types of behaviors in modern oceanography. While such behaviors may occur, modern oceanography is conducted under stronger anti-harassment policies that include anti-sexual harassment training at the beginning of cruises and clear reporting procedures, should an event occur (UNOLS, 2009). These policies are intended to provide safety for all cruise participants and to empower those who may experience adverse conditions in the field, as knowledge of such resources can be critical (Jahren, 2014).

Women also continue, on average, to earn less than men in academia. While a career in science can be immensely rewarding for those who have a passion to search for knowledge and find solutions to applied problems, it can be less rewarding in terms of financial support. In the United States, women earn an average of $17 \%$ less than male colleagues in science and engineering occupations at all degree levels (NSF, 2013; Shen, 2013), and an average of $24 \%$ less in occupations requiring a doctoral degree (Table 1). Even when controlling for other variables such as age and institution type, the inequality in salary is still significant. In the EU, women earn 25-40\% less than men (European Commission, 2009; Shen, 2013). Part of this discrepancy may be attributed to the cultural phenomenon of women not asking for raises, as has been discussed in studies of negotiation and the gender divide (Babcock and Laschever, 2003). Another reason for the disparity is the lower likelihood of women holding senior faculty ranking (West and Curtis, 2006).

In academia, women are more likely than men to encounter the "two-body problem," as the percentage of female academics with a partner who is also an academic or professional is higher than it is for male academics with academic or professional partners (Schiebinger et al., 2008). This challenge is enhanced for female academic scientists, as shown in a study that found $83 \%$ of female scientists with a partner were partnered with another academic, whereas this percentage was only $54 \%$ for male scientists (Schiebinger et al., 2008).

Starting and raising a family also pose unique challenges to women. Growing evidence documents that having children, or even planning to have them, coincides with both lower rates of women applying for and obtaining tenuretrack jobs (Wolfinger et al., 2008) and higher rates for leaving research (Goulden et al., 2009; Shen, 2013). Of the women who remain in academia, female faculty have fewer children, on average, than their male colleagues, and fewer than they desire (Ecklund and Lincoln, 2011; Shen, 2013). One explanation for this phenomenon is that having a family is a higher burden on women than on men (Handelsman et al., 2005). The often-insufficient support offered to families by many US institutions contributes to this burden. For example, there are different levels of personal (i.e., family) leave offered at 
different levels of academia: fewer resources are available to graduate students than to postdoctoral scientists or faculty (Goulden et al., 2009). Beyond leave issues, there are also differences in other family resources, such as organized childcare or extended tenure clocks. A career in science often requires frequent moves to new institutions and universities to work with experts, which can be challenging for those who wish to start a family because they may lack help with childcare in an unfamiliar environment. Moreover, it is more difficult for breastfeeding women to be able to participate in the daylong or off-site meetings commonly required in academia. Family-unfriendly policies significantly impact a woman's choice to stay in academia (Rosser and O'Neil Lane, 2002), and may in part explain the leak in the pipeline at the transition from assistant to associate professor (Table 1).

Fieldwork also presents unique challenges for women considering starting a family, beyond general issues of being separated from young children during formative stages of their lives. These include the possibility of going to sea while pregnant, and accommodation for lactation while at sea. There is a dearth of formal information available to US women regarding whether or not they can participate in research cruises while pregnant, and under what circumstances (e.g., allowable if a ship is within a certain distance of shore, or if there is a medical doctor on board, or depending on stage of pregnancy, or at the discretion of captains or chief scientists). For example, as of the summer of 2014, UNOLS, the program that coordinates the US oceanographic research fleet, does not have a formal policy regarding pregnant women going to sea. (By comparison, the US Antarctic Program has a policy that pregnancy is a "not physically qualified" condition for working at any time and at any station or on research vessels in Antarctica.) The lack of a formal policy leads to misinformation or worse-women choosing to go to sea while pregnant and hiding this information, which can be dangerous for all involved if there is an emergency. There are even fewer resources available for women who have recently given birth and may want to pump breast milk while at sea (e.g., insufficient private lactation space on board, non-existent facilities for storing collected breast milk). There are alternative solutions for some of these issues, such as sending a student or technician to sea in place of a pregnant or breastfeeding female scientist; however, these options can be limiting for early career women who lack the financial resources to support these alternatives, and potentially counterproductive for a woman who needs at-sea experience to become a chief scientist on a future expedition.

In recognition of some of these issues, the NSF provides funding specifically to support and promote women in faculty and leadership positions through the ADVANCE program started in 2001 (see Holmes, 2014, in this supplement for a more detailed discussion of the ADVANCE program) and the Career-Life Balance (CLB) Initiative launched in 2012. Over $\$ 230$ million has been awarded through these programs to date. In addition, some recent NSF policy changes (as of December 26, 2014) permit charges to all NSF grants for dependent-care expenses, such as daycare, that are above and beyond normal expenses as long as the institution allows such costs (see http://www.nsf.gov/pubs/policydocs/pappguide/nsf15001/sigchanges.jsp). NSF allows CLB supplements to existing grants for salaries for project personnel who replace individuals on a leave of absence due to dependent care (see CLB FAQs at http://www.nsf.gov/ pubs/policydocs/clb/clbfaqs.jsp). It is unclear how successful ADVANCE-enabled female recruiting will be at retaining female faculty in the long term, but evidence suggests that the program is having some impact (Holmes, 2014, in this supplement).

\section{RECOMMENDATIONS FOR OVERCOMING MODERN CHALLENGES FOR WOMEN IN ACADEMIC OCEANOGRAPHY}

To secure the pipeline of women working toward tenuretrack and senior-scientist positions, and to retain women in oceanography in particular, we provide the following recommendations.

1. Institutions should solicit the names of women at the search committee phase when hiring for new positions to help avoid unconscious gender bias that may work against women being named as potential candidates (West and Curtis, 2006; Moss-Racusin et al., 2012).

2. University departments and mentors should be more proactive in educating master's and doctoral students about the possibility of extending tenure clocks and professor rank expectations to allow family leave, so that female students know that there can be support networks for having children while staying in academia. Others take this one step further and recommend that institutions consider leveraging resources to provide on-site daycare for faculty (Ecklund and Lincoln, 2011). 
3. Faculty should be mindful of proven unconscious gender bias by both sexes, and of how diminished competency judgments, rewards, and mentoring may discourage female students and junior faculty from successfully competing for higher ranking career positions (Handelsman et al., 2005; Moss-Racusin et al., 2012).

4. Institutions are encouraged to have written policies for hiring and retaining dual-career academic couples, and even to announce dual-career opportunities in recruitment materials.

5. People in positions of authority-such as department chairs, directors, and deans-should ensure that all employees follow appropriate codes of conduct and sexual harassment prevention policies in the laboratory and in the field, with clear mechanisms for reporting incidences of harassment (Clancy et al., 2014), and they should ensure that common discrimination pitfalls are avoided.

6. All scientists should be mindful of common gender bias in such things as selection of plenary speakers at conferences (Kappel and Thompson, 2014, in this issue) and work toward unbiased and more representative gender distribution (Martin, 2014).

7. Women should harness the power of support groups and social media to surround themselves with female role models, and they should seek mentoring. We encourage women oceanographers to embrace these mechanisms by, for example, joining programs that promote and support women in marine science (the Society for Women in Marine Science is one example), actively engaging in social media groups focused on women in oceanography and other science fields, and participating in mentoring programs such as Mentoring Physical Oceanography Women to Increase Retention (Clem et al., 2014 , in this issue).

8. Institutions are encouraged to "recognize the financial constraints fieldwork places on young parents, and explore alternative ways of supporting young parents in the field" (Bell et al., 2005). For example, the Earth Institute at Columbia University has made additional research assistance available for women during family-life "transitional" periods (such as childbirth) and has enabled childcare for women needing to be in the field (Bell et al., 2005).
9. We encourage UNOLS to adopt a formal policy related to the ability of pregnant women to participate in seagoing fieldwork that is not overly restrictive and is based on sound scientific and medical advice. In cases where expedition length or timing precludes safe participation by young mothers or mothers-to-be, we encourage women to speak with their departments or program managers about options for supporting additional personnel to participate as their representatives. We highlight the increasing use of telepresence that in some cases could enable young parents to participate in fieldwork remotely (Fundis et al., 2012; Van Dover et al., 2012).

10. We encourage program managers involved in evaluating proposals that include ship time requests to explore whether proposals with female leads are disproportionately unsuccessful, and if so, whether there are mechanisms to address this issue.

\section{CONCLUSION}

There have been some promising improvements in the representation of women in oceanography over the past decade, as seen in the percentage increases in females in academia and as chief scientists (Figures 1, 2; Tables 1, 2), but more work needs to be done to even the field, especially at top levels. This article highlights opportunities to advocate for the career needs of female oceanographers. We end by acknowledging the recent promotion of several women to top-level positions related to oceanography-such as directors of oceanographic programs, administrators of federal programs, program managers, and chief editors of science magazines, as discussed in more detail elsewhere (O'Connell, 2014, in this supplement). We hope their success is an indication of sustained change that will encourage women to remain active in the field of oceanography.

ACKNOWLEDGEMENTS. This article is dedicated to the memories of Victoria Bertics and Katrina J. Edwards, two exceptional female oceanographers who inspired many to pursue their passions. The authors would like to thank Annette DeSilva for assistance with UNOLS data; Rainer Knust of the Alfred Wegner Institute for Polarstern data; Romain Troublé for Tara data; Natalie Arena for Alliance data; and the website managers of deepseadrilling.org, odp.tamu.edu, iodp.org and the Schmidt Ocean Institute for making data publicly available. The authors thank L. Lapham, K. Lloyd, P. Matrai, and R. Poretsky for their comments on an earlier version of this manuscript, as well as our handling editor Amelia Shevenell, editor Ellen Kappel, and four reviewers for their in-depth comments that brought this manuscript to completion, and Mary Anne Holmes for input on the ADVANCE and CLB programs. The authors are also indebted to supporters of \#womeninscience and \#ladiesinSTEM social media fora for sharing information that motivated this project. 


\section{REFERENCES}

Aschwanden, C. August 11, 2014. Harassment in science, replicated. The New York Times.

Babcock, L., and S. Laschever. 2003. Women Don't Ask: Negotiation and the Gender Divide. Princeton University Press, 240 pp.

Bell, R., J. Laird, S. Pfirman, J. Mutter, R. Balstad, and M. Cane. 2005. An experiment in institutional transformation: The NSF ADVANCE Program for Women at the Earth Institute at Columbia University. Oceanography 18(1):25-34, http://dx.doi.org/10.5670/oceanog.2005.67.

Bonatti, E., and K. Crane. 2012. Oceanography and women: Early challenges. Oceanography 25(4):32-39, http://dx.doi.org/10.5670/oceanog.2012.103.

Casadevall, A., and J. Handelsman. 2014. The presence of female conveners correlates with a higher proportion of female speakers at scientific symposia. mBio 5(1):e00846-13, http://dx.doi.org/10.1128/mBio.00846-13.

Clancy, K.B.H., R.G. Nelson, J.N. Rutherford, and K. Hinde. 2014. Survey of Academic Field Experiences (SAFE): Trainees report harassment and assault PLoS ONE 9(7):e102172, http://dx.doi.org/10.1371/journal.pone.0102172.

Clem, S., S. Legg, S. Lozier, and C. Mouw. 2014. The impact of MPOWIR: A decade of investing in mentoring women in physical oceanography. Oceanography 27(4) supplement:39-48, http://dx.doi.org/10.5670/ oceanog.2014.113.

Ecklund, E.H., and A.E. Lincoln. 2011. Scientists want more children PLoS ONE 6(8):e22590, http://dx.doi.org/10.1371/journal.pone.0022590.

European Commission. 2009. She Figures 2009: Statistics and Indicators of Gender Equality in Sciences. EUR 23856, Publications Office of the European Union, Luxembourg, 160 pp.

Fundis, A.T., D.S. Kelley, G. Proskurowski, and J.R. Delaney. 2012. Maximizing ship-to-shore connections via telepresence technologies. Abstract \#ED21B-0717, American Geophysical Union, Fall Meeting 2012, San Francisco, CA, USA.

Goulden, M., K. Frasch, and M.A. Mason. 2009. Staying Competitive: Patching America's Leaky Pipeline in the Sciences. Berkeley Center on Health, Economic, \& Family Security, The University of California, Berkeley, Berkeley, CA, USA, $52 \mathrm{pp}$.

Handelsman, J., N. Cantor, M. Carnes, D. Denton, E. Fine, B. Grosz, V. Hinshaw, C. Marrett, S. Rosser, D. Shalala, and J. Sheridan. 2005. More women in science. Science 309:1,190-1,191, http://dx.doi.org/10.1126/science.1113252.

Hill, C., C. Corbett, and A. St. Rose. 2010. Why so Few? Women in Science, Technology, Engineering and Mathematics. American Association of University Women, Washington, DC, 109 pp, http://www.aauw.org/ files/2013/02/Why-So-Few-Women-in-Science-Technology-Engineering-andMathematics.pdf.

Holmes, M.A. 2014. Advancing women in oceanography: How NSF's ADVANCE program promotes gender equity in academia. Oceanography 27(4) supplement:30-38, http://dx.doi.org/10.5670/oceanog.2014.112.

Isbell, T., T. Young, and A. Harcourt. 2012. Stag parties linger: Continued gender bias in a female-rich scientific discipline. PLoS ONE 7(11):e49682, http://dx.doi.org/10.1371/journal.pone.0049682.

Jahren, A.H. September 18, 2014. Science's sexual assault problem. The New York Times.

Kappel, E.S., and L. Thompson. 2014. Invited scientific papers and speakers and fellow awardees: Little progress for women oceanographers in the last decade. Oceanography 27(4) supplement:24-28, http://dx.doi.org/10.5670/ oceanog.2014.110.

Larivière, V., C. Ni, Y. Gingras, B. Cronin, and C.R. Sugimoto. 2013. Bibliometrics: Global gender disparities in science. Nature 504:211-213, http://dx.doi.org/10.1038/504211a.

Lavoie, D., and D. Hutchinson. 2005. The US Geological Survey: Seagoing women. Oceanography 18(1):39-46, http://dx.doi.org/10.5670/ oceanog.2005.69.

Lozier, M.S., 2005. A community effort toward the retention of women in physical oceanography. Oceanography 18(1):35-38, http://dx.doi.org/10.5670/ oceanog.2005.68.

Marcus, N. 2005. Oceanography, science, and academia: Women making a difference. Oceanography 18(1): 51-55, http://dx.doi.org/10.5670/ oceanog.2005.71.

Martin, J.L. 2014. Ten simple rules to achieve conference speaker gender balance. PLoS Computational Biology 10(11):e1003903, http://dx.doi.org/10.1371/ journal.pcbi.1003903.

Moss-Racusin, C.A., J.F. Dovidio, V.L. Brescoll, M.J. Graham, and J. Handelsman. 2012. Science faculty's subtle gender biases favor male students. Proceedings of the National Academy of Sciences of the United States of America 109(41):16,474-16,479, http://dx.doi.org/10.1073/ pnas.1211286109.
NSF (National Science Foundation). 2012. Report of the 2012 Committee of Visitors: Research and Education Programs, Division of Ocean Sciences: Years 2009-2011. http://www.nsf.gov/geo/adgeo/advcomm/fy2012_cov/ oce-geo-ocean-sciences-edu-report-2012.pdf

NSF. 2013. Women, Minorities, and Persons with Disabilities in Science and Engineering. National Science Foundation, National Center for Science and Engineering Statistics, NSF 13-304, Arlington, VA, http://www.nsf.gov/ statistics/wmpd/2013/start.cfm.

O'Connell, S. 2014. Women of the academy and the sea: 2000-2014. Oceanography 27(4) supplement:15-22, http://dx.doi.org/10.5670/ oceanog. 2014.108

O'Connell, S., and M.A. Holmes. 2005. Women of the academy and the sea. Oceanography 18(1):12-24, http://dx.doi.org/10.5670/oceanog.2005.66.

Park, S.M. 1996. Research, teaching, and service: Why shouldn't women's work count? Journal of Higher Education 67(1):46-84.

Rosser, S.V., and E. O'Neil Lane. 2002. Key barriers for academic institutions seeking to retain female scientists and engineers: Family-unfriendly policies, low numbers, stereotypes, and harassment. Journal of Women and Minorities in Science and Engineering 8:161-189.

Schiebinger, L., A.D. Henderson, and S.K. Gilmartin. 2008. Dual-Career Academic Couples: What Universities Need to Know. Michelle R. Clayman Institute for Gender Research, Stanford University, 108 pp.

Schuster, J.H., and M.J. Finkelstein. 2006. The American Faculty: The Restructuring of Academic Work and Careers. The Johns Hopkins University Press, Baltimore, MD, $600 \mathrm{pp}$

Sheltzer, J.M., and J.C. Smith. 2014. Elite male faculty in the life sciences employ fewer women. Proceedings of the National Academy of Sciences of the United States of America 11:10,107-10,112, http://dx.doi.org/10.1073/ pnas.1403334111.

Shen, H. 2013. Inequity quantified: Mind the gender gap. Nature 495:22-24, http://dx.doi.org/10.1038/495022a.

Thompson, L., R.C. Perez, and A.E. Shevenell. 2011. Closed ranks in oceanography. Nature Geoscience 4:211-212, http://dx.doi.org/10.1038/ngeo1113.

UNOLS (University-National Oceanographic Laboratory System). 2009. Research Vessel Safety Standards, 9th ed. UNOLS, University of Rhode Island-Graduate School of Oceanography, Narragansett, RI, USA, 145 pp., http://www.unols.org/sites/default/files/2009RVSS_ web2012updates\%281\%29.pdf.

Van Dover, C.L., C.R. German, D.R. Yoerger, C.L. Kaiser, and L. Brothers. 2012. Telepresence field research experience for undergraduate and graduate students: An R/V Okeanos Explorer/AUV Sentry success story. Abstract \#OS51D-1909, American Geophysical Union, Fall Meeting 2012, San Francisco, CA, USA.

Wennerås, C., and A. Wold. 1997. Nepotism and sexism in peer-review. Nature 387:341-343, http://dx.doi.org/10.1038/387341a0.

West, M.S., and J.W. Curtis. 2006. AAUP Faculty Gender Equity Indicators. American Association of University Professors, Washington, DC, $84 \mathrm{pp}$.

Wolfinger, N.H., M.A. Mason, and M. Goulden. 2008. Problems in the pipeline: Gender, marriage, and fertility in the Ivory Tower. The Journal of Higher Education 79(4):388-405, http://dx.doi.org/10.1353/jhe.0.0015.

AUTHORS. Beth N. Orcutt (borcutt@bigelow.org) is Senior Research Scientist, Bigelow Laboratory for Ocean Sciences, East Boothbay, ME, USA Ivona Cetinić is Research Scientist, School of Marine Sciences, University of Maine, Walpole, ME, USA. 